\title{
Regional neonatal intensive care: bias and benefit
}

\author{
TEYRNON G POWELL, PETER O D PHAROAH
}

\begin{abstract}
Among very low birthweight infants born to residents of Merseyside in 1979-81 those booked at or transferred in utero to the regional unit were more likely to survive than those born elsewhere in the region. A study was carried out to determine whether the increased survival rate was attributable to better care or differences in the babies treated at the unit, or both. Four subpopulations were defined by district of maternal residence to obtain fairly comparable samples. Survival to 2 years increased as proportions treated at the regional unit increased, this "doseresponse" effect being most pronounced among the smallest infants. Despite less favourable social state infants from the district housing the regional unit were apparently in the best condition at birth; had been managed most actively before, at, and after birth; and were the most likely to survive. This increased survival, however, was associated with a marginally significant increase in prevalence of major impairments.

These data underline the need for routine surveillance of large representative samples of low birthweight survivors.
\end{abstract}

\section{Introduction}

The House of Commons Social Services Committee has recommended that every health region should have a unit equipped and staffed to provide the best possible intensive care for mother, fetus, and infant. ${ }^{1}$ There has, however, been no randomly controlled trial of the benefit of transferring infants, before or after birth, to such units. ${ }^{2}$ A study of the outcomes of infants weighing $2000 \mathrm{~g}$ or less who were born to residents of Merseyside during $1979-81^{3}$ enabled us to examine these outcomes in relation to treatment at the Mersey regional unit. We compared the survival of infants of birth weight 501-1500 $\mathrm{g}$ who were booked to be born at the unit, transferred there before birth, transferred there after birth, or not treated there. Why did the four groups have different survival rates? Was it because of a difference in quality of care or differences in the babies treated at the unit? Similarly, why did the survival rates in some of the groups change from 1979 to 1981 ? We could not answer these questions. To examine the effects of treatment at the regional unit we needed to compare the outcomes of similar groups of infants.

The data permitted such a comparison: the sample of infants comprised separate, geographically defined subpopulations, different proportions of which had been treated at the regional unit. We present the survival rates in the different groups of infants and the effect of increased referral to the regional unit on the survival rate ("dose-response" relation).

\section{Subjects and methods}

The sample comprised all liveborn infants of birth weight $501-2000 \mathrm{~g}$ born during 1979-81 to residents of five adjacent health districts in the Mersey region. The infants were identified from birth notification forms and

Department of Community Health, University of Liverpool, PO Box 147, Liverpool L69 3BX

TEYRNON G POWELL, MA, MRCP, researcher

PETER O D PHAROAH, MD, FFCM, professor

Correspondence to: Professor Pharoah. validated by examining hospital records. Data on the characteristics of mothers and infants and details of all interhospital transfers were gathered from hospital case records.

Infant survival was defined as survival to 2 years of age; it was ascertained either from hospital records or in the course of tracing neonatal survivors for assessment. Survivors were assessed between 3 years of age and school entry for major neurological impairment, which was defined as cerebral palsy, shunted hydrocephalus, epilepsy, educational subnormality, or visual or hearing loss. (The latter three impairments were identified by the need for special schooling.) Of 1074 infants who survived to 2 years, 1010 were assessed in their homes and 32 by means of written information from parents and other doctors; we were unable to contact 32 children.

For the first part of the analysis significance of differences in survival between two groups of infants was tested by the $\chi^{2}$ test with Yates's correction. Significance of linear trends in survival among more than two groups was tested by the $\chi^{2}$ test for trend.

For the second part of the analysis the sample was divided into four subpopulations according to district of maternal residence. One of the five health districts in the area studied (north Sefton) was combined with another (south Sefton) owing to the small sample size. The other districts were Liverpool, St Helens-Knowsley, and Wirral. We reasoned that if the populations were similar a consistent relation between proportions treated at the unit (dose) and proportions surviving (response) would be evidence of cause and effect. We looked for this dose-response effect among each $500 \mathrm{~g}$ birthweight group (501-1000 g, 1001-1500 g, and 1501-2000 g). Thus the proportions of each of the four populations that had been treated at the regional unit were plotted against the proportions of infants who survived. The $\chi^{2}$ test for trend was used to test the significance of the trend in survival that had been plotted.

We then considered whether the populations were similar up to the first day of life. Characteristics of mothers and infants from Liverpool were compared with those of mothers from the other combined districts by the $\chi^{2}$ test with Yates's correction and the Mann-Whitney or Student's $t$ test. Logistic regression analysis ${ }^{4}$ was used to test whether residence in Liverpool was associated with increased survival independently $(p<0 \cdot 1)$ of the differences between the populations, which would suggest that its effect was mediated in the neonatal period.

\section{Results}

\section{OUTCOMES OF DIFFERENT GROUPS OF INFANTS}

Table I shows the trends in perinatal care in the area studied during 1979-81: increasing numbers of very low birthweight infants ( $1500 \mathrm{~g}$ or less) were treated at the regional unit. In 1979 the survival of infants transferred in utero to the unit was poor by comparison with that of infants kept in the district hospitals, but survival increased after 1979 as the proportion of infants transferred increased. From the perspective of the regional unit this resulted in an increase in the combined survival rate of all its infants, but there was no significant increase in survival rate for the population as a whole. Furthermore, among extremely low birthweight infants $(1000 \mathrm{~g}$ or

TABLE I-Trends in numbers (percentages) of liveborn infants of very low birth weight surviving to 2 years according to place of birth or treatment, 1979-81

\begin{tabular}{|c|c|c|c|c|}
\hline & 1979 & 1980 & 1981 & $\begin{array}{l}\text { p Value for } \\
\text { trend in } \\
\text { survival }\end{array}$ \\
\hline $\begin{array}{l}\text { Booked and born at unit } \\
\text { Transferred in utero } \\
\text { Transferred postnatally }\end{array}$ & $\begin{array}{r}20 / 31(65) \\
5 / 12(42) \\
4 / 19(21) \\
\end{array}$ & $\begin{array}{l}\text { Region } \\
22 / 36(61) \\
15 / 28(54) \\
9 / 24(38)\end{array}$ & $\begin{array}{l}\text { al unit } \\
26 / 36(72) \\
32 / 45(71) \\
14 / 27(52)\end{array}$ & $\begin{array}{l}\text { NS } \\
0.04 \\
0.03\end{array}$ \\
\hline Total & $29 / 62(47)$ & $46 / 88(52)$ & $72 / 108(67)$ & $<0.01$ \\
\hline Not treated at regional unit & $80 / 138(58)$ & $\begin{array}{l}\text { District } \\
49 / 99(50)\end{array}$ & $\begin{array}{l}\text { rospitals } \\
53 / 97 \text { (55) }\end{array}$ & NS \\
\hline All infants & $109 / 200(55)$ & $95 / 187(51)$ & $125 / 205(61)$ & NS \\
\hline
\end{tabular}


less), though the combined survival of all those treated at the regional unit also increased significantly after $1979(p=0.03)$, that of those not admitted to the unit fell significantly (not shown) $(p=0 \cdot 03)$. There was a net increase in survival for the whole population of infants of extremely low birth weight, but it was not significant.

During the whole study period the survival of extremely low birthweight infants transferred in utero to the regional unit was higher than that of those born elsewhere $(p=0.05)$ (table II). Very low birthweight infants booked

TABLE II-Numbers (percentages) of liveborn infants surviving to 2 years by birth weight and place of treatment (1979-81 inclusive)

\begin{tabular}{lrrr}
\hline & \multicolumn{3}{c}{ Birth weight (g) } \\
\cline { 2 - 4 } & $501-1000$ & $1001-1500$ & $1501-2000$ \\
\hline Booked and born at regional unit & $13 / 35(37)$ & $55 / 68(81)$ & $116 / 130(89)$ \\
Booked elsewhere: & & & \\
Transferred in utero to regional unit & $10 / 29(35)$ & $42 / 56(75)$ & $20 / 22(91)$ \\
Transferred postnatally to regional unit & $5 / 29(17)$ & $22 / 41(54)$ & $26 / 34(77)$ \\
Not treated at regional unit & $18 / 109(17)$ & $164 / 225(73)$ & $579 / 629(92)$ \\
\hline
\end{tabular}

and therefore born at the regional unit fared better than those booked elsewhere $(p=0 \cdot 03)$. Similarly, very low birthweight infants born at the regional unit (those booked there and those transferred in utero) were more likely to survive than infants born elsewhere $(p<0 \cdot 01)$. For infants born in the district hospitals postnatal transfer to the regional unit was a marker of increased mortality for those of birth weight $1501-2000 \mathrm{~g}(\mathrm{p}<0.01)$ and $1001-1500 \mathrm{~g}(\mathrm{p}=0.02)$ but not for extremely low birthweight infants.

\section{DOSE-RESPONSE ANALYSIS}

Survival rates increased as proportions treated at the regional unit increased; the dose-response effect was progressively less pronounced as birth weight increased (figure). Table III shows, however, that the risk of very low birthweight infants surviving with an impairment also increased as proportions treated at the regional unit increased. This was due mostly to the effect of increased survival rate as prevalence of impairment per livebirth= survival rate $\times$ prevalence of impairment per survivor. There was also, however, an increase in prevalence of impairment per survivor; it was not significant, but numbers were small.

TABLE III-Outcomes of four populations of infants weighing 501-1500 $\mathrm{g}$ and proportions treated at regional unit

\begin{tabular}{lccccc}
\hline & \multicolumn{4}{c}{ Population $^{\star}$} \\
\cline { 2 - 5 } & $\begin{array}{c}\text { St Helens- } \\
\text { Knowsley }\end{array}$ & Sefton & Wirral & Liverpool & $\begin{array}{c}\text { p Value } \\
\text { (trend) }\end{array}$ \\
\hline No of live births & 187 & 78 & 107 & 220 \\
No(\%) treated at regional unit & $55(29)$ & $24(31)$ & $37(35)$ & $141(64)$ \\
No(\%) of liveborn infants who: & & & & & \\
$\quad$ Died & $94(50)$ & $38(49)$ & $47(44)$ & $84(38)$ & 0.012 \\
Survived with impairment & $8(5)$ & $4(6)$ & $7(7)$ & $19(9)$ & $0.085(N S)$ \\
Survived without impairment & $85(45)$ & $36(46)$ & $53(49)$ & $117(53)$ & $0.096(N S)$ \\
No(\%) of survivors with impairment & $8(9)$ & $4(10)$ & $7(12)$ & $19(14)$ & $0.2(N S)$ \\
\hline
\end{tabular}

^ Defined by district of maternal residence.

The very low birthweight infants from Liverpool, which houses the regional unit, had the highest survival rate. When various obstetric variables were compared there were no significant differences between very low birthweight infants born in Liverpool and those born elsewhere in birth weight, gestational age, sex, multiple births, malformations, maternal age, previous pregnancies, smoking, antepartum haemorrhage, induction of labour, use of oxytocics or tocolytics (drugs to stop labour progressing), length of labour, caesarean births, or breech deliveries. There were, however, differences in several other characteristics (table IV).

District of residence (Liverpool or the three others combined) had a significant effect on survival when it was entered into a logistic regression model in the presence of birth weight, gestational age, and the other significant factors known on the first day of life. In other words the higher survival rate of infants in Liverpool remained significant $(p<0.01)$ after birth weight, gestational age, and the other differences between the populations had been allowed for.
TABLE IV-Significant differences between infants of residents of Liverpool and the three other districts. Values are numbers (percentages) of liveborn infants of birth weight $501-1500 \mathrm{~g}$

\begin{tabular}{lcrr}
\hline & \multicolumn{2}{c}{ Population } & \\
\cline { 2 - 3 } & \multicolumn{1}{c}{$\begin{array}{c}\text { St Helens-Knowsley, } \\
\text { Sefton, and Wirral }\end{array}$} & \multicolumn{1}{c}{ Liverpool } & p Value \\
\hline Unemployed father & $46 / 182(25)$ & $51 / 132(39)$ & 0.02 \\
Manually employed & $104 / 177(59)$ & $90 / 124(73)$ & $0 \cdot 02$ \\
Hospital booking before labour & $344 / 372(92)$ & $214 / 220(97)$ & 0.02 \\
Hypertension in pregnancy & $61 / 365(17)$ & $22 / 217(10)$ & 0.05 \\
If vertex vaginal and forceps used & $52 / 181(29)$ & $46 / 110(42)$ & 0.03 \\
1 Minute Apgar score=9 or 10 & $38 / 349(11)$ & $40 / 213(19)$ & 0.01 \\
5 Minute Apgar score=9 or 10 & $124 / 309(40)$ & $102 / 193(53)$ & $<0.01$ \\
Intubated at birth & $179 / 365(49)$ & $129 / 216(60)$ & 0.02 \\
Umbilical artery catheter inserted & $120 / 360(33)$ & $105 / 214(49)$ & $<0.01$ \\
Ventilated in neonatal unit: & $179 / 365(49)$ & $129 / 216(60)$ & $<0.02$ \\
$\quad$ Within one hour of birth & $103 / 163(63)$ & $89 / 118(75)$ & 0.04 \\
Treated in regional unit & $115 / 372(31)$ & $141 / 220(64)$ & $<0.01$ \\
Survived & $194 / 372(52)$ & $137 / 220(62)$ & 0.02 \\
\hline
\end{tabular}

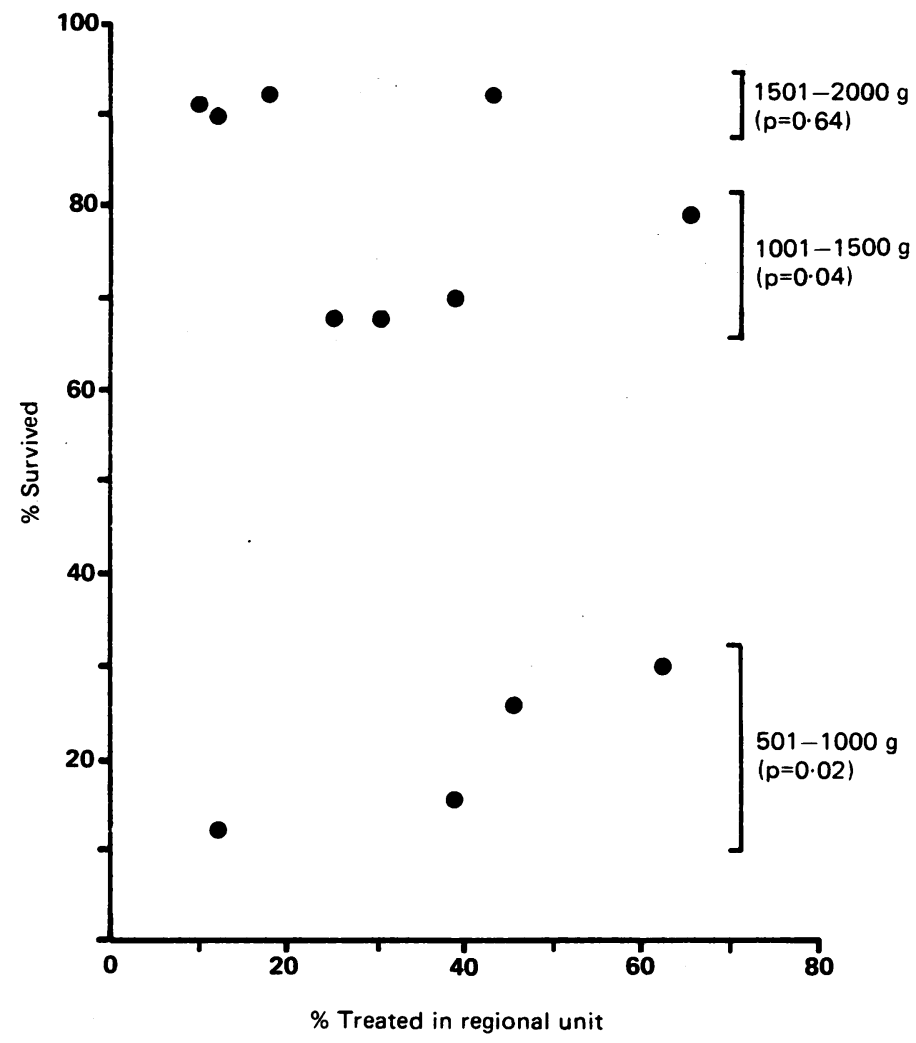

Trends in survival to 2 years among four populations of infants in relation to birth weight and proportion treated at regional unit. $p$ Values are for $\chi^{2}$ for trend.

\section{Discussion}

To assess the benefit from a treatment, the outcome in a treated group must be compared with the outcome in an otherwise similar untreated group. Infants transferred and those not transferred to a regional unit are not similar: transfer implies either that infants are sick or that they are likely to become sick. This bias would occur in prospective or retrospective studies of the groups. Confounding differences could be controlled statistically, provided that the sample was large enough both to allow this and to retain enough statistical power to show a significant difference in outcome. Unmeasured or unrecognised differences in the samples, however, could not be controlled in this way.

Clinical logic must be used to guess whether survival differed between groups (tables I and II) because of differences in care or in the babies, or both. It might be that the relatively low survival of infants transferred weighing $1501-2000 \mathrm{~g}$ was the result of these 
babies being more ill, although this does not mean that transferred infants did not benefit from transfer. By contrast, it might be that small infants transferred in utero did fairly well because they benefited from care at the regional unit, but in utero transfer might imply the selection of relatively healthy fetuses.

Similarly, the higher survival of infants booked to be born at the regional unit must be interpreted with caution: healthier and more middle class women with their babies may be attracted by the better reputations of better units. ${ }^{5}$ Regionalisation of perinatal care may add to the bias inherent in analysis of samples of infants treated at regional units. ${ }^{6}$ The Mersey regional unit may have been pleased with the improvement in its results after 1979, but this was attributable to infants transferred from elsewhere; owing to the policy of regionalisation relatively low risk infants may have accounted for an increasing proportion of the infants transferred to the unit.

Surveillance of the long term outcomes of perinatal care has been carried out mostly by those who also devote their energy to providing care at individual hospitals. These data, however, underline the need for monitoring the outcomes of geographically defined populations.

Our dose-response analysis is a poor substitute for a randomly controlled trial of transferring small infants to a regional unit, but groups of infants selected by area of residence should at least be more similar than groups selected by treatment. Our subpopulations were not as similar as we had hoped, but we doubt that the demographic differences favoured the infants of Liverpool, who had the highest survival rate. Others have shown that the survival of geographically defined populations of low birthweight infants is related to the facilities available for their care. ${ }^{78}$ In a Swedish study the survival of infants born to residents of areas containing hospitals with specialised obstetric and neonatal units was not higher than that of infants from areas containing maternity hospitals with no specialised neonatal units. ${ }^{9}$ The effect of the Mersey regional unit on survival was powerful but was most apparent among the smallest infants. This was expected because these are the infants most in need of intensive care.

Infants from Liverpool had better Apgar scores than other infants and, according to the data, had been managed more actively before and after birth. Apparently there is room to improve care at the district hospitals either before birth or on the resuscitation trolley. Residence in Liverpool had a significant effect on survival that was apparently mediated either by differences in neonatal care or by unknown differences in the populations. Is it logical that the effect was mediated by differences in neonatal intensive care?

The increased prevalence of impairments in children from Liverpool was not significant but was worrying: the increase might have been significant if the sample had been larger. This leads us again to the urgent need for routine surveillance of large, representative samples of survivors. Unbiased data on both antecedents and outcomes would allow unbiased analysis of the aetiology of impairments. The information might allow us not only to observe but also to predict the long term consequences of keeping very small infants alive.

We thank the Department of Health and Social Security for funding the work; our statistician, Mr Christopher West; and Dr Richard Cooke for his suggestions and advice.

\section{References}

1 Social Services Committee. Second report from the Social Services Committee 1979-80: perinatal and neonatal mortality. Vol 1. London: HMSO, 1980.

2 Crowley P. Preterm birth-some clinical dilemmas. In: Chiswick ML, ed. Recent advances in perinatal medicine 2. Edinburgh: Churchill Livingstone, 1985:19-38.

3 Powell TG, Pharoah POD, Cooke RWI. Survival and morbidity in a geographically defined population of low birthweight infants. Lancet 1986;: $539-43$.

4 Nelder JA, Wedderburn RWM. Generalised linear models. Foumal of the Royal Statistical Sociery [A] 1972;135:370-84.

5 Sackett DL. Bias in analytical research. 7 Chronic Dis 1979;32:51-63.

6 Chiswick ML, Davies P, Bate R, Dryburgh E, Gordon-Nesbitt D. Regional organisation of neonatal intensive care in the north-west. BrMed $\mathcal{f} 1979 ;$ ii:247-50.

7 Usher R. Changing mortality rates with perinatal intensive care and regionalisation. Semin Perinatol 1977;1:309-19.

8 Bakketeig LS, Hoffman HJ, Sternthal PM. Obstetric service and perinatal mortality in Norway. Acta Obstet Gynecol Scand 1978;77(suppl):3-19.

9 Eksmyr R, Eklund G. Early neonatal deaths in geographically defined populations with different organization of medical care. Acta Paediatr Scand 1985;74:848-54.

(Accepted 10 fune 1987)

\section{ONE HUNDRED YEARS AGO}

The character this hospital has of late years acquired in Dublin for bad management, and for other circumstances of a more personal nature connected with its administration, seems, unfortunately, to be getting worse. Notwithstanding the recent additions to the Board of a large number of governors, the business, we are informed, is transacted in such a manner as already to have caused some of these gentlemen to resign their position in disgust. The want of funds is no sufficient excuse for the state in which the hospital is. We understand that it has been without an operation-theatre and suitable dispensary accommodation for about two years, and the resident students have to occupy one of the wards. There is hardly any class attending the hospital, and the available number of beds in it is under fifty. Last September, a gentleman who was acting as locum tenens for one of the resident pupils, but who, it was stated, was not a pupil of the hospital, made certain charges in writing to the Governors against officials of the hospital. A committee was appointed to investigate these charges, but it did not examine the student who made them, nor any of the witnesses he was prepared to bring forward in support of them. The committee reported the charges were not proved; and a resolution was passed, authorising the Registrar to prevent the person who had the hardihood to make any charges against the management of the hospital from entering it. This extraordinary conduct of the Board caused such a manifestation of public feeling, that it was obliged to pass a resolution asking the corporation to nominate three gentlemen publicly to investigate the aforesaid charges. The corporation acceded to this request, and appointed three of its members, who, however, were induced to hold a private inquiry into the matter. They have reported to the corporation in terms entirely white-washing the hospital, and declaring that its management is "effective and humane," and that every official connected with it is "active and efficient." At the same time that this private inquiry was being conducted a magisterial investigation on oath was going on in one of the Police Courts in connection with the same matter. This was in the shape of a summons against the resident surgeon "for that he did grievously assault and accelerate and cause the death of' a man who had been a patient in the hospital. As this case is still before the magistrate, we refrain from making any further comment upon it at present. It was a most irregular proceeding to publish the result of the private inquiry by the corporation, while a public magisterial one was being held. Whatever may be the decision arrived at by the latter, we fancy it will be viewed with greater respect by the public than that conducted by the corporation. (British Medical Fournal 1887;i:228.)

Correspondents not infrequently write to complain of the hardships which they suffer owing to the very inadequate remuneration allowed to medical expert witnesses by courts of law. It is perhaps a poor consolation to know that others are in harder case, but the experiences of a practitioner in Texas, quoted in the New York Medical Record, are worse than anything which can be endured in this country. He was summoned at midnight by a deputy sheriff to examine the victim of an alleged rape; on the following day he was commanded to go to the county seat, ten miles distant, to repeat the examination. He was detained for several days at his own expense, then allowed to return to his practice, then summoned again. This was repeated. more than once, and, finally, the jury disagreed. The unfortunate witness, after this, moved to another town 150 miles away, and there one day he was arrested by the sheriff, and taken in custody to the town where a second trial was being held. The trial was adjourned, and the witness was bound down under a heavy penalty to appear when wanted. In order not to forfeit his bond, he had to keep himself in telegraphic communication with the legal officials, and in one way and another spent and lost about $£ 40$. In the end the case was dismissed, and the medical witness received nothing. Lawyers have a saying that "hard cases make bad law;" but such hard cases as this, and some others which have recently been reported in our own columns, show the badness of the existing law both in this country and in the United States. (British Medical Fournal 1887;i:73.) 